\title{
A Review on Macrophage Activation Syndrome
}

\section{Preeti Sharma ${ }^{1 *}$, Shailza Shreshtha ${ }^{1}$, Pradeep Kumar ${ }^{1}$ and Rachna Sharma ${ }^{2}$ and \\ T.K. Mahapatra ${ }^{1}$}

${ }^{1}$ Department of Biochemistry, Santosh Medical College and Hosipital, Ghaziabad - 201 001, India. ${ }^{2}$ Department of Biochemistry, TSM Medical College and Hospital, Lucknow - 226 003, India.

\begin{abstract}
MAS, which is currently grouped under secondary or acquired haemophagocytic lymphohistiocytosis (sHLH), is a rare and fatal disorder that results from excess activation of T-cells and macrophages. Though the pathogenesis of MAS is poorly understood, various proinflammatory cytokines like interleukins (IL-1, IL-6), tumor necrosis factor $\alpha$ (TNF $\alpha$ ), interferons are thought to play significant roles. MAS is associated with various clinical features such as non-remitting fever, bleeding, cytopenias, splenomegaly, hepatic dysfunctions, increased levels of triglyceride, ferritin and decreased levels of albumin and fibrinogen. Early diagnosis and interventions are crucial to reduce mortality risk but diagnosis is not often easy due to persistence of wide range of features that overlap with other rheumatic diseases, most commonly SIIA (systemic juvenile idiopathic arthritis). Corticosteroids and cyclosporins are commonly used for MAS treatment. Intravenous immunoglobulins, biologic agents like IL-1 blockers (anakinra, canakinumab), IL-6 blockers (tocilizumab) are also frequently used. Moreover there is still the need of genetic and immunohistological study in order to understand the exact mechanism of the syndrome development and establishment of novel therapies with lesser toxicities.
\end{abstract}

Keywords: MAS, haemophagocytic lymphohistiocytosis, systemic juvenile idiopathic arthritis, cytokines, corticosteroids.

*Correspondence: prcdri2003@yahoo.co.in

(Received: 14 January 2019; accepted: 23 February 2019)

Citation: Preeti Sharma, Shailza Shreshtha, Pradeep Kumar and Rachna Sharma, A Review on Macrophage Activation Syndrome, J Pure Appl Microbiol., 2019; 13(1):183-191 doi: 10.22207/JPAM.13.1.19

(c) The Author(s) 2019. Open Access. This article is distributed under the terms of the Creative Commons Attribution 4.0 International License which permits unrestricted use, sharing, distribution, and reproduction in any medium, provided you give appropriate credit to the original author(s) and the source, provide a link to the Creative Commons license, and indicate if changes were made. 


\section{INTRODUCTION}

Various autoimmune and inflammatory states are known to be associated with a number of life threatening conditions. One of them is Macrophage activation syndrome ${ }^{1}$, that is more commonly observed in rheumatic diseases such as systemic juvenile idiopathic arthritis (sJIA), Kawasaki disease, systemic lupus erythro-matosus (SLE), Still's disease, juvenile dermato-myositis and Becket's disease ${ }^{2,3,4}$

MAs does not hold a recent history. Familial lymphohistocytosis that shares quite similar clinical picture to MAS was first observed in $1952^{5}$. Later, Boone in 1976, reported MAS among the patients with compulsive coagulopathy and hepatic insufficiency ${ }^{5}$ but Stephen et al was the one who coined the term Macrophage activation syndrome in 1993 and demonstrated that the excess activation of macrophages in most of his patients 6 . MAS that develops as a result of excess activation of macrophages, is emerging as a well characterized clinical facet that may be associated with different drugs, infections, cancers, hematological and rheumatic disorders or any isolated disease occurring with or without trigger?.

Prevalence

Though a rare complication, MAS has become more common these days. In a study from tertiary care hospital about $6.7 \%$ cases of SJIA had MAS ${ }^{8}$. MAS is more frequently observed in children but increased prevalence is also present in adults nowadays ${ }^{9}$. It is a life threatening disorder with mortality rate of $20-30 \%{ }^{10}$. Among the rheumatologic disorders, SJIA is most commonly associated with $\mathrm{MAS}^{11}$ with the prevalence rate of $7-13 \%{ }^{12}$, but the rate may vary upto $30-40 \%$ in the unreflected cases of $\mathrm{MAS}^{13}$. According to Gormezano et al, MAS is also frequently associated with SLE in children with acute pancreatitis and they have higher mortality rate in comparison to those having SLE only ${ }^{14}$.

The incidence of MAS is also high in ASOD that closely resembles SJIA. It is reported to be 7.7-16\% with the mortality rate ranging between $9.5-22 \%{ }^{15}$. The incidence of MAS in SLE is about $0.9-4.6 \%{ }^{16}$.

\section{Features of MAS}

The clinical features of MAS evolve rapidly. The common signs and symptoms

presented by the patients are non-remitting high fever, hepatomegaly, splenomegaly. Neuropsychiatric dysfunction, lymphadenopathy, pancytopenia, skin erythema, anemia and less frequent abnormalities of heart, kidneys and lung tissues $^{17,7,18}$ (Table 1).

Table 1. Signs and symptoms of MAS ${ }^{20}$

\begin{tabular}{lc}
\hline Features & Incidence \\
\hline Fever & $95 \%$ \\
Arthritis & $64 \%$ \\
Hemorrhagic & $20 \%$ \\
abnormalities & \\
Lymphadenopathy & $51 \%$ \\
Hepatomegaly & $70 \%$ \\
$\begin{array}{l}\text { Splenomegaly } \\
\text { Neurologic }\end{array}$ & $55 \%$ \\
dysfunction & $34 \%$ \\
Involvement of tissues & $10 \%$ \\
(heart, lung, kidney) & \\
\hline
\end{tabular}

Table 2. Laboratory changes in MAS

Investigations Changes

1. Hematological profile

Hemoglobin

White blood

cell count

Platelet count

INR and PTT

ESR

\section{Biochemical profile}

Ferritin

D-dimer

Liver enzymes

LDH

TG

SCD 25 (receptor for

IL-2) and SCD 163

(receptor for

hemoglobin- haptoglobin

complex) Fibrinogen

\section{Histopathological} changes

Bone marrow biopsy
Decreases

Decreases

Decreases

Increases

Decreases

Increases

Increases

Increases

Increases

Increases

Increases

Decreases

Increased hemophagocytic macrophages with elevations in CD163 
The laboratory results in MAS are not specific, however the frequently observed changes (Table 2) are increase in hepatic enzymes, bilirubin, triglycerides, ferritin, D-dimer and lactate dehydrogenase while there is decrease in levels of sodium, hemoglobin, blood cells like leucocytes and platelets, albumin, fibrinogen, clotting factors like II, VII and X. Patients also show elevated partial thrombo-plastin time along with the presence of degradation product of fibrinogen. Levels of various cytokines are also found to be elevated. Some of the examples are interleukins (IL-1, IL-2, IL-6), tumor necrosis factor $\alpha$ (TNF $\alpha$ ), interferons (INF $\alpha$, INF $\gamma$ ) and macrophage colony stimulating factor (MCSF) $)^{17}$.

Bone marrow biopsy shows the highly elevated number of well differentiated macrophages that actively phagocytize hematopoietic cells. However hemophagocytosis may not be detectable during the initial stages and may lack sensitivity in $40 \%$ of cases $^{19}$. Other tissues like lymph node, spleen and liver also exhibit

Table 3. Diagnostic criteria of MAS as formulated in $2004^{18}$

\section{Criterias}

1. Molecular diagnosis having specific gene mutation consistent with HLH

2. Clinical and laboratory criteria (5 out of 8 are to be met $\rightarrow 2$ clinical and 3 laboratory)

A. Clinical

i. Fever

ii. Splenomegaly

B. Laboratory

i. Cytopenia

a. Hemoglobin

(infant $<4$ weeks)

b. Platelets

c. Neutrophils

ii. Hypertriglyceridemia and/or hypofibrinogenemia

iii. Hemophagocytosis

iv. Decreased or absence of NK cell activity

v. Increased ferritin

vi. Increased soluble CD25 (II-2 receptor)

$<9 \mathrm{gm} / \mathrm{dl}$ (adult), $<10 \mathrm{gm} / \mathrm{dl}$

$<10 \times 10^{9} / \mathrm{dl}$

$<1 \times 10^{8} / \mathrm{dl}$

$>265 \mathrm{mg} / \mathrm{dl}$

$<0.15 \mathrm{gm} . \mathrm{dl}$

Bone marrow aspirate, spleen or lymph nodes $->500 \mathrm{mg} / \mathrm{dl}$ $>2400 \mathrm{U} / \mathrm{ml}$ hemophagocytic pattern but these sites are rarely explored in literatures.

\section{Type of MAS}

MAS is basically categorized as subtype of secondary hemophagocytic-lymphohisto-cytosis $(\mathrm{sHLH})^{21}$. HLH is broadly categorized into two distinct types as:

Primary HLH ( inherited or familial form)

Secondary HLH ( acquired form) ${ }^{19,22}$.

Primary $\mathrm{HLH}$ is autosomal recessive in nature with high incidence in infants ( $80 \%$ cases) compared to adults ${ }^{23}$. It is characterized by the following features:

Defective T-cell activation

Defective NK cell mediated cytolytic pathway

Excess production of cytokines that result in uncontrolled activation T-cells and macrophages ${ }^{24}$.

Secondary HLH can occur at any ages due to excess immunological activation as a result of various infections caused by viruses (Epstein barr, Herpes simplex, Varicellazoster), bacteria (Hemophilus, Mycobacterim, Brucela), fungus (candida, Histoplama), parasites (Leishmania), drugs, hematological malignancies and autoimmune inflammatory disorders ${ }^{22,25}$.

Table 4. Diagnostic criteria for MAS complicating sJIA

Criteria Changes

A. Clinical

1. Neurologic dysfunction

2. Hemorrhages

3. Hepatomegaly

B. Laboratory

Decreases

platelet count

Headache, lethargy, irritability, disorientation, seizures and come Purpura, ecchymoses and mucosal bleeding Liver enlargement $\geq 3 \mathrm{~cm}$ below coastal margin

Decreased $\quad \leq 4 \times 10^{6} / \mu \mathrm{l}$

leucocyte count

Decreased fibrinogen level Increased AST $<250 \mathrm{mg} / \mathrm{dl}$

$\leq 262 \times 10^{6} / \mu \mathrm{l}$

$>59 \mathrm{U} / \mathrm{L}$ 
Table 5. EULAR/ACR criteria for MAS in SJIA

Patients with sJIA having

1. a. Fever

b. Increased ferritin

2. And any two of the

following criterias

i. Platelet count

ii. AST level

iii. Triglyceride level

iv. Fibrinogen level

\section{Diagnosis}

It is often difficult and challenging to properly diagnose MAS as it can mimic infections or malignancies or may be present as the complications of SJIA. Diagnosis is also difficult in ealrly phases due to lack of pathognomic clinical findings. In 1991, the criteria for diagnosis of MAS was first proposed by a scientific team studying histocyte disorders. These criterias were later modified in $2004{ }^{25}$. According to this modified diagnostic guideline, the patient is supposed to be suffering from MAS if any one of the following characteristics is met:

Presence of gene mutations (PRF, UNC13D, STX11) associated with $\mathrm{HLH}^{18}$ or
5 out of 8 laboratory and clinical diagnostic criterias. These include cytopenia, increased levels of triglyceride/fibrinogen, hemophagocytosis, low or absence of NK cell activity. Increase in ferritin and soluble CD25, fever and hepatospleenomegaly ${ }^{21}$ (Table 3).

However, several researches have focused on challenges in applying 2004 diagnostic criteria for MAS, as SJIA, the most frequently associated rheumatologic disorder with $\mathrm{MAS}^{26}$ is independently associated with hyperferritinemia, anemia ${ }^{27}$ and leucocytosis ${ }^{28}$ in absence of MAS. Such overlap of clinical features may pose difficulty in early diagnosis of MAS onset ${ }^{29}$. Likewise coagulopathies which are not only common in $\mathrm{MAS}^{30}$ but also in other disorders can further complicate the sample collection procedure for histological diagnosis ${ }^{25}$. To address these issues, Raveli et al. ${ }^{7}$ proposed a preliminary diagnostic criteria for MAS associated with SJIA in 2005. According to this guideline, diagnosis of MAS needs the fulfillment of $\geq 2$ laboratory and $\geq 2$ clinical criterias (Table 4).

The preliminary diagnostic guideline of Raveli et al were assessed by Davi et al, who compared it with that of 2004 diagnostic guidelines. They concluded that preliminary

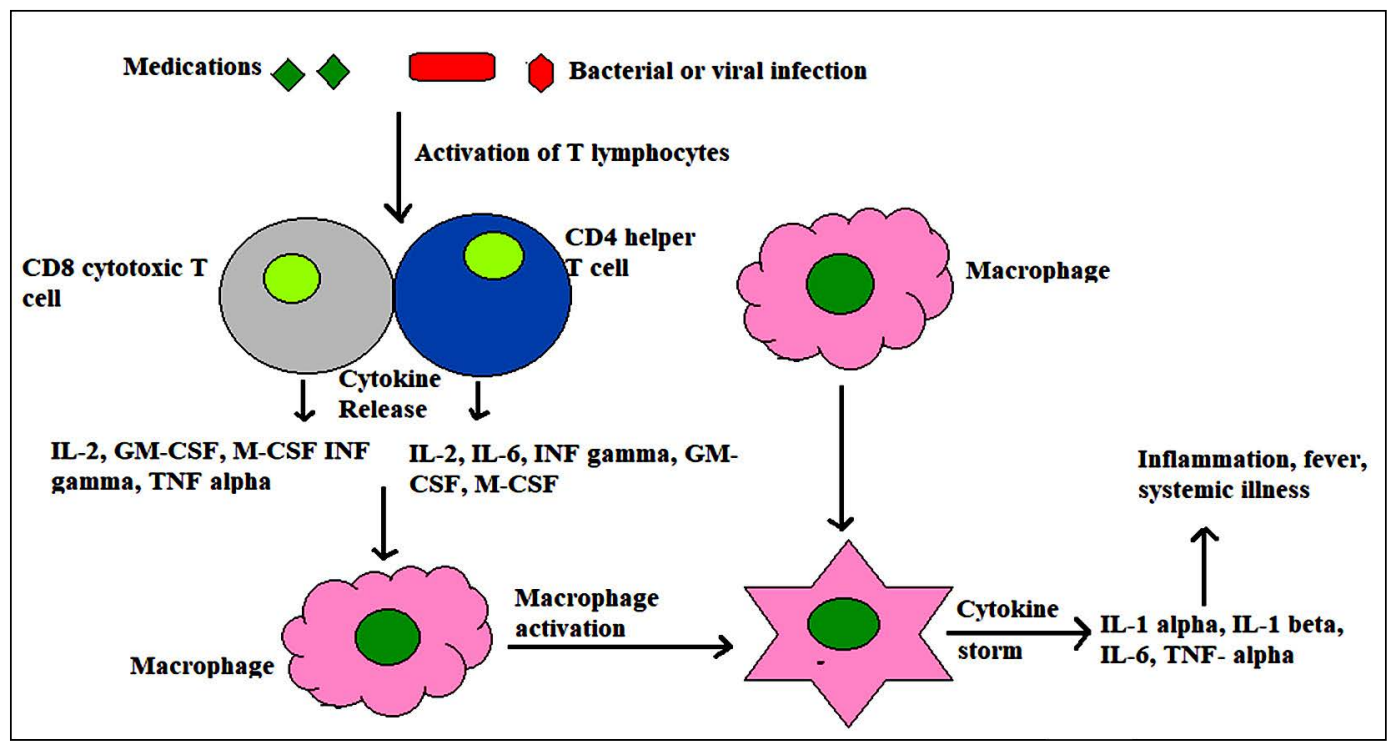

Fig. 1. Macrophage activation syndrome induced by infections and medications. Under the stimulation of bacterial, viral or fungal infection and certain medicines, T cells are activated and may directly induce apoptosis of both activated macrophages and/or T cells themselves. It results in dysregylation of cytotoxic activities causing persistent of macrophages and T cells leading to cytokine storm. 
diagnostic criteria showed best results with high sensitivity and specificity of $86 \%^{31}$. Another diagnostic criteria for MAS associated with SJIA as also approved by European league agains Rheumatism/ American College of Rhematology (EULAR/ACR) in 2016 (Table 5) $^{32,33}$.

\section{Cytokine storm in MAS}

Many studies have reported high levels of cytokines, TNF receptors and IL-1R antagonists in $\mathrm{MAS}^{34}$. Cytokines present include proinflam-matory cytokines like those derived from lymphocytes (INF $\gamma, \mathrm{IL}-2$ ) and cytokines produced by monocytes and macrophages (IL$1 \beta$, TNF $\gamma$, IL-6 and IL-18). Regulatory cytokines such as IL-10 are also elevated in $\mathrm{MAS}^{34}$. Patients with severe MAS may disturb the regulatory pathways of IL-10 which can lead to uncontrolled inflammation. Stimulation of toll like receptor 9 along with blockade of IL-10 receptor can lead to more severe complications ${ }^{35}$.

IL-1 $\alpha$, a proinflammatory cytokine, is considered to be the central one in pathogenesis of disease. It is initially secreted in an inactive form but when cells are activated, caspase-1 protein cleaves pro IL1 $\alpha$ to its active form. On activation, it causes further activation of lymphocytes and endothelial cells thereby stimulating production of other inflammatory cytokines like IL- $6^{36}$.

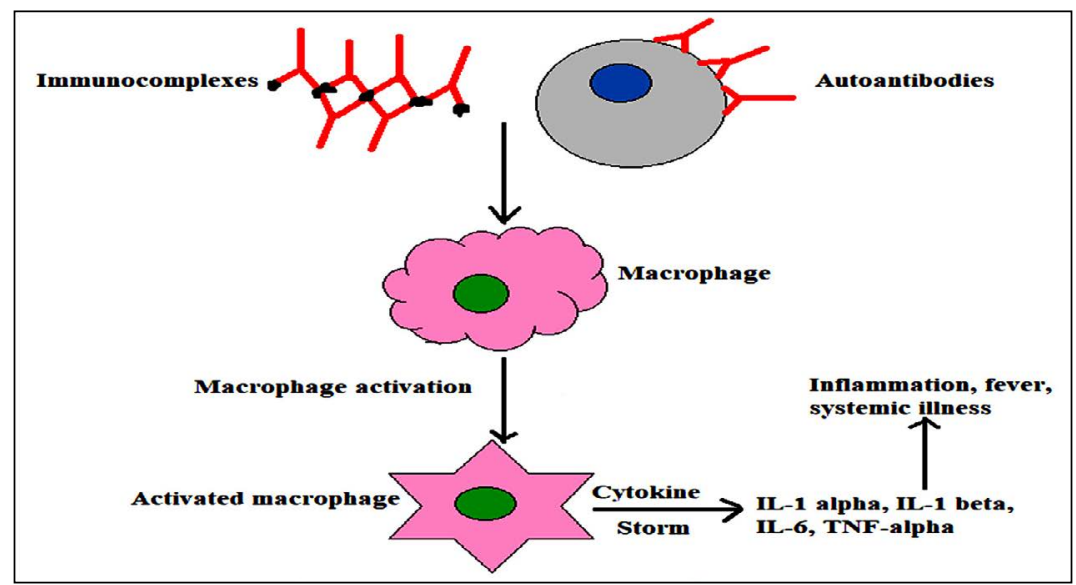

Fig. 2. Auto-antibodies or immune complexes can also stimulate macrophages resulting in production of enormous amount of cytokines

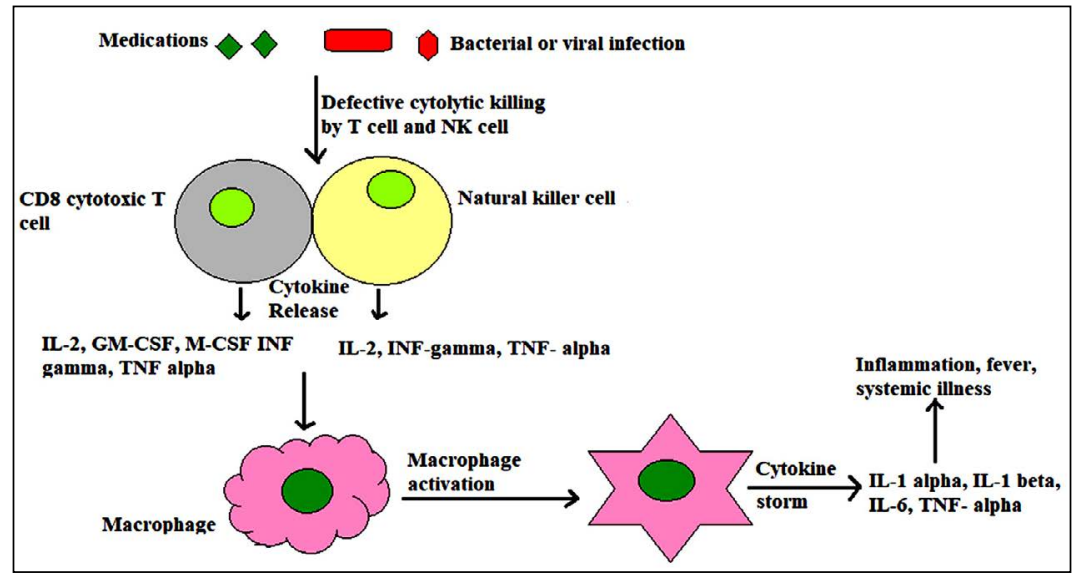

Fig. 3. Failure of cytolytic killing mechanism of T cells and NK cells due some genetic defects (such as defect in perforin gene), can also promote MAS, as defective cytotoxicity casuses continuum of antigenic stimulation leading to persistent $\mathrm{T}$ and NK cell activation and proliferation. Cytokines are persistently released from activated cells that further stimulate macrophages leading to cytokine storm. 


\section{Pathophysiology}

The etiology and specific pathogenesis of MAS are yet to be clearly elucidated. However most of the theories derived rely on the study of primary HLH which is clinically quite similar to MAS. It is stated that hemophagocytosis can develop due to dysregulation of immunologic phenomenons resulting in the exaggeration of inflammatory responses which is characterized by excessive activation of macrophages and $T$ lymphocytes that ultimately leads to cytokine storm $^{37}$.

It has been reported that numerous proinflammatory cytokines are released. It is also demonstrated that hyperactive T- cells and macrophages reside in various organs and produce cytokines like INF $\gamma$, TNF $\alpha$, IL-6 and IL- 1 which play a major role in pathogenesis of MAS. The condition is further aggravated by the presence of perforin deficiency ${ }^{38}$. Perforin is a type of cytotoxic protein secreted by T- cells and NK cells to destroy virus infected cells. It is also involved in regulation of lymphocyte prolife-ration. Mutation in gene coding for perforin is linked with MAS as it can lead to T-cell and NK cell dysfunction ${ }^{39,40}$ and persistent

Table 6. Major cytokines inducing MAS

\begin{tabular}{|c|c|}
\hline Cytokines & Roles \\
\hline IL-1 $\alpha$ and & $\begin{array}{l}\text { Co-stimulation of T cell } \\
\text { and antigen presenting cell }\end{array}$ \\
\hline IL-1 $\beta$ & $\begin{array}{l}\text { Acute phase response } \\
\text { Fever and inflammation } \\
\text { Hematopoeisis }\end{array}$ \\
\hline IL-2 & $\begin{array}{l}\text { Proliferation and activation } \\
\text { of B cells, } T \text { cells and NK cells }\end{array}$ \\
\hline IL-6 & $\begin{array}{l}\text { Proliferation pf B cell } \\
\text { Acute phase response } \\
\text { Stimulation of T cells } \\
\text { synergistically with TNF- } \alpha \\
\text { and IL-1 }\end{array}$ \\
\hline INF- $\gamma$ & $\begin{array}{l}\text { Promotes cell mediated } \\
\text { immunity } \\
\text { Activates neutrophils, NK } \\
\text { cells and macrophages }\end{array}$ \\
\hline TNF- $\alpha$ & $\begin{array}{l}\text { Activates signaling pathways } \\
\text { that cause proliferation of } \\
\text { immune cells }\end{array}$ \\
\hline and M- CSF & $\begin{array}{l}\text { Stimulate proliferation and } \\
\text { differentiation of dendritic } \\
\text { cells and } \\
\text { monocytes }\end{array}$ \\
\hline
\end{tabular}

lymphocyte activation ${ }^{38}$.

IL-1 $\beta$ via its receptors signals production of IL- $6^{41}$ that plays a central role in inducing acute phase response ${ }^{40}$. Some researchers have shown that imbalance between IL-18 and its inhibitor results in activation of macrophages and Th-1 lymphocytes that have bypassed NK cell mediated cytotoxic control, leading to the manifestation of sHLH ${ }^{43-42}$. IL-18 belongs to IL-1 family and stimulates the production of INF $\gamma$ (by NK cells and T-cells), TNF $\gamma$ and chemokines (by macrophages) ${ }^{41}$. The major role of INF $\gamma$ is to cause profound activation of macrophages and monocytes. The increased levels of INF $\gamma$ is also well correlated with clinical and laboratory features of $\mathrm{MAS}^{43}$.

\section{Treatment}

There is necessity of urgent management of MAS. The preliminary purpose of the therapy used should be control of hyper inflammatory state with the use of immunosuppressive or cytotoxic drugs. The most commonly used drugs are corticosteroids and cyclosporins. However other therapeutic agents like etanercept, etoposide, immunoglobins in high dose and plasmapheresis are also used in practice ${ }^{44}$.

Steroids such as methylprednisolone and dexamethasone are the first line drugs of choice as the response of patients is usually prompt. However steroids are rarely used as monotherapy for long term due to their side effects ${ }^{45}$. In case of MAS unresponsive to steroids alone, a combination therapy consisting of steroids and cyclosporine is given. Cyclosporin is an inhibitor of T-cell function and mostly administered in early stage of the syndrome ${ }^{25}$. It also has membrane stabilizing effect on macrophages ${ }^{46}$.

Etoposide is a bone marrow suppressant and its use can result in severe infection, therefore caution is to be taken in patients having renal or hepatic impairment ${ }^{47}$. As per Coca et al, antithymocyte globulin (ATG) could be used in place of etoposide ${ }^{48}$ but it may be associated with infusion reactions ${ }^{49}$.

In case of MAS associated with SJIA, IL-1 inhibitor (such as anakinra) is being used increasingly $y^{50}$. Though the exact role of IL-1 in pathogenesis of MAS is unclear, it is expected that IL-1 inhibition may aid in better control of the disease. According to the several reports, II-1 inhibitors have proven better treatment choice in 
MAS complicating SJIA, which showed inadequate response to cyclosporins and corticosteroids ${ }^{51}$.

Successful treatment of MAS associated with ASOD using IL-1 blockers have also been documented ${ }^{46}$. However according to the recent report, of 23 patients with SJIA who were treated with anakinra, one patient developed $\mathrm{MAS}^{52}$ and in another report it was stated that anakinra might have triggered MAS in 5 out of 46 patients of $s J A^{53}$. IL- 6 blockers (like tocilizumab) is also used as the treatment strategy among the patients who could not tolerate IL-146.

Activated macrophages produce IL- 6 which may further amplify the macrophage response to the proinflammatory stimuli ${ }^{54}$. However, as per the Japaneses study, tocilizumab when used in the treatment of ASOD gradualy progressed the patient to $\mathrm{MAS}^{55}$. Reports regarding development of cytopenias following the use of tocilizumab in patients with sJIA (complicated with MAS) are also available ${ }^{56}$. Rituximab and intravenous Igs have shown satisfactory results in MAS induced by viruses like Epstein barr virus and cytomegalo virus $^{57}$.

\section{CONCLUSION}

MAS, though rare, is a potentially fatal disorder that requires prompt and appropriate treatment to prevent deleterious outcomes. Since there is lack of valid criteria for the diagnosis of MAS, the treatment appears highly variable at different clinical sectors. However the most commonly used treatment is the use of corticosteroids as monotherapy or along with cyclosporins or immunoglobulins. In some cases use of etoposide and IL-1 bockers are also recommended.

As MAS is mostly associated with rheumatic disease, clinicians should be aware of diagnostic principle and management. It is necessary to understand the underlying pathophysiology of MAS in order to identify the pathways involved in early phase of the syndrome so that better ideas could be developed in furnishing newer treatment biomarkers. Additionally larger cohorts regarding immunological and genetic studies must be carried out to formulate more effective and appropriate therapy as well as to improve mortality. Also studies have shown that the cytokine storm is the main driving force for pathology of hyper-inflammatory syndromes. Therefore therapeutic approaches blocking cytokine function might be fruitful with less toxic effects.

\section{ACKNOWLEDGEMENT}

None

\section{CONLFICT OF INTEREST}

The authors declares that there is no conflict of interest.

\section{REFERENCES}

1. Behrens EM, Beukelman T, Paessler M, Cron RQ. Occult macrophage activation syndrome in patients with systemic juvenile idiopathic arthritis. J. Rheumatol., 2007; 34(5): 1133-8.

2. Jain D, Agrawal HK, Rao A, Mittal A, Jain P. Macrophage activation syndrome in a patient with systemic onset of the juvenile idiopathic arthritis. Reumatologia, 2016; 54 (1): 42-7.

3. Granata G, Didona D, Stifano G, Fiola A, Granata M. Macrophage Activation Syndrome as Onset of Systemic Lupus Erythematosus: A Case Report and a Review of the Literature. Case Rep Med., 2015; 294041: 1-4.

4. Wakiguchi $H$, Hasegawa $S$, Hirano R, Kaneyasu $H$, Takahara MW, Ohga S. Successful control of juvenile dermatomyositis-associated macro-phage activation syndrome and interstitial pneumonia: distinct kinetics of interleukin-6 and -18 levels. Pediatr. Rheumatol. Online J., 2015; 13(11): 49.

5. Gary Sterba,Yonit Sterba, Antonio Iglesias G. Macrophage activation syndrome in adults with rheumatic disease. Rev colomb reumatol., 2016; 23(2): 137-43.

6. Henter J, Todini C, Pritchard J. Histiocyte disorders. Crit Rev Oncol Hematol., 2004; 50(2): 157-74.

7. Ravelli A, Magni-Manzoni S, Pistorio A, Besana C, Foti T, Ruperto N, Viola $S$ et al. Preliminary diagnostic guidelines for macrophage activation syndrome complicating systemic juvenile idiopathic arthritis. J. Pediatr., 2005; 146(5): 598-604.

8. Stephan JL, Kone-Paut I, Galambrun C, et al. Reactive haemophagocytic syndrome in children with inflammatory disorders. A retrospective study of 24 patients. Rheumatology (Oxford), 2001; 40(11): 1285-92.

9. Ieni E, Cetica V, Piccin A, Gherlinzoni F, Sasso FC, Rabusin $M$ et al. Familial hemophagocytic lymphohistiocytosis maypresent during adult-hood: clinical and genetic features of asmall series. PLoS One, 2012;7(9): e44649 (1-5).

10. S Sawhney, P Woo, K J MurrayMacrophage activation syndrome: a potentially fatal complication of rheumatic disorders. Arch Dis Child, 2001; 85(5): 421-6.

11. Pringe A, Trail L, Ruperto N, Buoncompagni A, Loy A, Breda L, Martini A, Ravelli A: Macrophage activation syndrome in juvenile systemic lupus erythematosus: an under-recognized compli-cation? Lupus, 2007; 16(8): 
587-92.

12. Deane S, Selmi C, Teuber SS, Gershwin ME. Macrophage activation syndrome in auto-immune disease. Int Archlmmunol., 2010; 153(2): 109-20.

13. Barut K, Yucel G, Sinoplu AB, Sahin S, Adrovic A Kasapcopur O. Evaluation of macrophage activation syndrome associated with systemic juvenile idiopathic arthritis: single center experience over a one-year period. Turk Pediatri Ars., 2015; 50(4): 206-10.

14. Gormezano NW, Otsuzi Cl, Barros DL, da Silva MA, Pereira RM, Campos LM et al. Macrophage activation syndrome: A severe and frequent manifestation of acute pancreatitis in 362 childhood-onset compared to 1830 adult-onset systemic lupus erythematosus patients. Semin Arthritis Rheum., 2016; 45(6): 706-10.

15. Watanabe E, Sugawara H, Yamashita T, Ishii A, Oda A, Terai $C$ et al. Successful tocilizumab therapy for macrophage activation syndrome associated with adult-onset Still's disease: a case-based review. Case Rep Med., 2016; 5656320: 1-7.

16. S Vilaiyuk, N Sirachainan, S Wanitkun, K Pirojsakul, J Vaewpanich. Recurrent macrophage activation syndrome as the primary mani-festation in systemic lupus erythematosus and the benefit of serial ferritin measurements: a case-based review. Clinical Rheumatology, 2013; 32(6): 899-904.

17. Ravelli A. Macrophage activation syndrome. Curr Opin Rheumatol., 2002; 14(5): 548-52.

18. Henter JI, Horne A, Arico M, Egeler RM, Filipovich $\mathrm{AH}$, Imashuku S. HLH-2004: diagnostic and therapeutic guidelines for hemophagocytic lymphohistiocytosis. Pediatric Blood and Cancer, 2007; 48(2): 124-31.

19. Arceci RJ. When T cells and macrophages do not talk: the hemophagocytic syndromes. Curr. Opin. Hematol., 2008; 15(4): 359-67.

20. C Scott. Macrophage activation syndrome. Current allergy and clinical immunology, 2016; 29(3): 198-201.

21. Manappallil RG. A Case of Macrophage Activation Syndrome with Acute Respiratory Distress Syndrome. J. Clin. Diagn. Res., 2016; 10(9): OD11-OD12.

22. Janka, G. Hemophagocytic lymphohistiocytosis: When the immune system runs amok. Klin. Padiatr., 2009; 221(5): 278-85.

23. Gupta S, Weitzman S. Primary and secondary hemophagocytic lymphohistiocytosis: clinical features, pathogenesis and therapy. Expert Rev. Clin. Immunol., 2010; 6(1): 137-54.

24. Weaver LK, Behrens EM. Hyperinflammation, rather than hemophagocytosis, is the common link between Macrophage Activation Syndrome and Hemophagocytic Lymphohistiocytosis. Curr Opin Rheumatol., 2014; 26(5): 562-9.

25. Stabile A, Bertoni B, Ansuini V, Torraca IL, Sallל A, Rigante $D$. The clinical spectrum and treatment options of macrophage activation syndrome in the pediatric age. European Review for Medical and Pharmacological Sciences, 2006; 10(2): 53-9.

26. Berkun $Y$, Padeh S. Macrophage activation syndrome in juvenile idiopathic arthritis; in Shoenfeld Y, Cervera R, Gershwin ME (eds): Diagnostic Criteria in Autoimmune Diseases. Totowa, Humana Press, 2008, pp 21-24.

27. Recalcati S, Invernizzi P, Arosio P, Cairo G. New functions for an iron storage protein: the role of ferritin in immunity and autoimmunity. J. Autoimmun. 2008; 30(1-2): 84-9.

28. Kelly A, Ramanan AV. Recognition and management of macrophage activation syndrome in juvenile arthritis. Curr. Opin. Rheumatol., 2007; 19(5): 477-81.

29. Behrens EM, Beukelman T, Paessler M, Cron RQ. Occult macrophage activation syndrome in patients with systemic juvenile idiopathic arthritis. J. Rheumatol., 2007; 34(5): 1133-8.

30. Schaer DJ, Schaer CA, Schoedon G, Imhof A, Kurrer MO. Hemophagocytic macrophages constitute a major compartment of heme oxygenase expression in sepsis. Eur. J. Haematol, 2006; 77(5): 432-6.

31. Davi S, Consolaro A, Guseinova D, Pistorio A, Ruperto $N$, Martini A et al. An international consensus survey of diagnostic criteria for macrophage activation syndrome insystemic juvenile idiopathic arthritis. J. Rheumatol., 2011; 38(5): 764-8.

32. Gupta A, Tyrrell P, Valani R, Benseler S, Weitzman $S$, Abdelhaleem $M$. The role of the initial bone marrow aspirate in the diagnosis of hemo-phagocytic lymphohistiocytosis. Pediatr Blood Cancer, 2008; 51(3): 402-4.

33. Ravelli A et al.; Paediatric Rheumatology International Trials Organisation; Childhood Arthritis Rheumatology Research Alliance; Pediatric Rheumatology Collaborative Study Group; Histiocyte Society. 2016 Classification Criteria for Macrophage Activation Syndrome Complicating Systemic Juvenile Idiopathic Arthritis: A European League Against Rheumatism/ American College of Rheu-matology /Paediatric Rheumatology International Trials Organisation Collaborative Initiative. Ann. Rheum. Dis., 2016; 75(3): 481-9.

34. Sumegi J, Barnes MG, Nestheide SV, Molleran-Lee S, Villanueva J, Zhang K et al. Gene expression profiling of peripheral blood mononuclear cells from children with active hemophagocytic lymphohistiocytosis. Blood, 2011; 117(15): e151-e160.

35. Behrens EM, Canna SW, Slade K, Rao S, Kreiger PA, Paessler $\mathrm{M}$ et al. Repeated TLR9 stimulation results in macrophage activation syndrome-like disease in mice. J. Clin. Invest, 2011; 121(6): 2264-77.

36. Villanueva J, Lee $S$, Giannini EH, Graham TB, Passo MH, Filipovich A, Grom AA. Natural killer cell dysfunction is a distinguishing feature of systemic onset juvenile rheumatoid arthritis and macrophage activation syndrome. Arthritis Res. Ther., 2005; 7(1): R30-R37.

37. Larroche C, Mouthon L. Pathogenesis of hemophagocytic syndrome. Autoimmunity Rev., 2004; 3(2): 69-75.

38. Jain D, Agrawal HK, Rao A, Mittal A, Jain P. Macrophage activation syndrome in a patient with systemic onset of the juvenile idiopathic arthritis. Reumatologia, 2016; 54(1): 42-7.

39. Vastert SJ van Wijk R, D'Urbano LE, de Vooght KM, de Jager W, Ravelli A et al. Mutations in the perforin gene can be linked to macrophage activation syndrome in patients with systemic onset juvenile idiopathic arthritis. Rheumatology (Oxford), 2010; 49(3): 441-9. 40. Grom AA, Villanueva J, Lee S, Goldmuntz EA, Passo 
$\mathrm{MH}$, Filipovich A. Natural killer cell dysfunction in patients with systemic-onset juvenile rheumatoid arthritis and macrophage activation syndrome. $J$. Pediatr., 2003; 142(3): 292-6.

41. Schulert GS, Grom AA. Macrophage activation syndrome and cytokine-directed therapies. Best Pract. Res. Clin. Rheumatol., 2014; 28(2): 277-92.

42. Shimizu $M$, Nakagishi $Y^{2}$, Inoue $N$, Mizuta $M$, Ko G, Saikawa $Y$ et al. Interleukin-18 for predicting the development of macrophage activation syndrome in systemic juvenile idiopathic arthritis. Clin. Immunol., 2015; 160(2): 277-81.

43. Bracaglia C, de Graaf K, Pires MD, Guilhot F, Ferlin W, Prencipe G. Elevated circulating levels of interferon- $\gamma$ and interferon- $\gamma$-induced chemokines characterise patients with macrophage activation syndrome complicating systemic juvenile idiopathic arthritis. Ann. Rheum. Dis., 2017; 76(1): 166-72.

44. Seidel MG, Kastner U, Minkow M, Gadner H. IVIG treatment of adenovirus infection associated macrophage activation syndrome in a two years old boy: case report and review of literature. Pediatr Hematol Oncol., 2003; 20(6): 445-51.

45. Minoia F, Davi S, Horne A, Bovis F, Davi S, , Demirkaya $E$, Akikusa J et al. Dissecting the heterogeneity of macrophage activation syndrome complicating systemic juvenile idiopathic arthritis. J. Rheumatol., 2015; 42(6): 994-1001.

46. Durand M, Troyanov $Y$, Laflamme P, Gregoire G. Macrophage activation syndrome treated with anakinra. J. Rheumatol., 2010; 37(4): 879-880.

47. G. Bosman, Langemeijer SMC, Hebeda KM, Raemaekers JMM, Pickkers P, Van der Velden WJFM. The role of rituximab in a case of EBV-related lymphoproliferative disease presenting with haemophagocytosis. Netherlands Journal of Medicine, 2009; 67(8): 364-5.

48. Coca A, Bundy KW, Marston B, Huggins J, Looney RJ. Macrophage activation syndrome: serological markers and treatment with anti-thymocyte globulin. Clinical Immunology, 2009; 132(1): 10-18.

49. Ali AK. Pharmacovigilance analysis of serious adverse events reported for biologic response modifiers used as prophylaxis against transplant rejection: a real- world postmarketing experience from the US FDA adverse event reporting system (FAERS). International Journal of Organ Trans-plantation Medicine, 2013; 4(2): 62-71.

50. Atteritano M, David A, Bagnato G, Beninati C, Frisina $A$, laria $C$ et al. Haemophagocytic syndrome in rheumatic patients. A systematic review. Eur. Rev. Med. Pharmacol. Sci., 2012; 16(10): 1414-24.

51. Kelly A, Ramanan AV. A case of macrophage activation syndrome successfully treated with anakinra. Nat. Clin. Pract. Rheumatol., 2008; 4(11): 615-20.

52. Zeft A, Hollister R, Lafleur B, Sampath P, Soep J, McNally $B$ et al. Anakinra for systemic juvenile arthritis: the Rocky Mountain experience. J. Clin. Rheumatol., 2009; 15(4):161-4.

53. Nigrovic PA, Mannion M, Prince FH, Zeft A, Rabinovich $C E$, van Rossum MA et al. Anakinra as first-line disease-modifying therapy in systemic juvenile idiopathic arthritis: report of forty-six patients from an international multicenter series. Arthritis Rheum., 2011; 63(2): 545-55.

54. Strippoli R, Carvello F, Scianaro R, De Pasquale L, Vivarelli M, Petrini S et al. Amplification of the response to Toll-like receptor ligands by prolonged exposure to interleukin-6 in mice: implication for the pathogenesis of macrophage activation syndrome. Arthritis Rheum., 2012; 64(5): 1680-8.

55. Kobayashi M, Takahashi Y, Yamashita H, Kaneko H, Mimori A. Benefit and a possible risk of tocilizumab therapy for adult-onset Still's disease accompanied by macrophage-activation syndrome. Mod. Rheumatol., 2011; 21(1): 92-6.

56. Kessler EA, Vora SS, Verbsky JW. Risk of significant cytopenias after treatment with tocilizumab in systemic juvenile arthritis patients with a history of macrophage activation syndrome. Pediatr Rheumatol Online J., 2012; 10(1): 30.

57. Tristano AG, Escalona LC, Torres A, Rodriguez MA. Macrophage activation syndrome in a patient with systemic onset rheumatoid arthritis: rescue with intravenous immunoglobulin therapy. Journal of Clinical Rheumatology, 2003; 9(4): 253-8. 